Article

\title{
Understanding the Relationships between Extensive Livestock Systems, Land-Cover Changes, and CAP Support in Less-Favored Mediterranean Areas
}

\author{
Laurence Delattre $^{1}$, Marta Debolini ${ }^{2, *(\mathbb{D})}$, Jean Christophe Paoli ${ }^{3}$, Claude Napoleone ${ }^{4}(\mathbb{D}$, \\ Michel Moulery ${ }^{4}$, Lara Leonelli ${ }^{5}(\mathbb{B})$ and Pierre Santucci ${ }^{3}$ \\ UMR 9221 LEM CNRS/Université de Lille, 59491 Villeneuve d'Ascq, France; laurence.delattre@univ-lille.fr \\ UMR 1114 EMMAH INRAE-AU, 84914 Avignon, France \\ 3 UR 0045 LRDE INRAE, 20250 Corte, France; jean-christophe.paoli@inrae.fr (J.C.P.); levitolu7@orange.fr (P.S.) \\ 4 UR Ecodeveloppement INRAE, 84914 Avignon, France; claude.napoleone@inrae.fr (C.N.); \\ michel.moulery@inrae.fr (M.M.) \\ 5 UMR 6134 SPE CNRS, Université de Corse, 20250 Corte, France; lara.leonelli@hotmail.fr \\ * Correspondence: marta.debolini@inrae.fr
}

Received: 15 October 2020; Accepted: 11 December 2020; Published: 14 December 2020

check for updates

\begin{abstract}
Farm abandonment and over-extensification trends in less-favored livestock breeding areas in the Mediterranean have led to socio-environmental issues that are difficult to assess and address, due to the characteristics of these areas (e.g., poor data availability and reliability). In a study case that presents many of the characteristics common to these areas, we combine qualitative and quantitative approaches to assess (i) the relationship between livestock production and land-cover change and (ii) the drivers of farmer decisions, concerning the types of livestock they breed. We show that the Common Agricultural Policy's objective of open-landscape preservation cannot be achieved through the observed livestock management practices, with the most heavily CAP subsidy-dependent activities (e.g., suckler-cow breeding) having one of the weakest contributions to this objective. We also econometrically show that suckler-cow breeding is more likely to be adopted as a complementary or main activity in farms facing a labor scarcity and land abundance context. These results complement the literature and contribute to the discussion regarding the design of CAP support for less-favored Mediterranean areas.
\end{abstract}

Keywords: Mediterranean mountainous landscape; farmer choice drivers; extensive livestock systems; Common Agricultural Policy; land-use change; less favored areas (LFA)

\section{Introduction}

In Mediterranean agricultural landscapes, a dual trend of intensification and extensification of livestock farming systems has been generally observed over the last few decades [1-5]. Intensification has occurred in the most accessible, easily mechanizable, and fertile lowland, while extensification has occurred in remote, sparsely populated, steep, or poor soil areas [6-8], where farming systems were already rather extensive (e.g., traditional sheep and goat breeding). In many regions of southern Europe, these extensive rangeland grazing systems (i.e., permanent pastures, generally of low productivity, often with a mix of herbaceous and non-herbaceous forage) represent a large proportion, or even the majority, of all farmland [9-12]. At the beginning of the 2000s, around $25 \%, 40 \%$, and $10 \%$, respectively, of the total E.U. sheep, goat, and cattle populations were bred in the EU-15 Mediterranean less-favored areas (LFA) [8]. In the last year, where not abandoned, marginal areas have experienced a shift toward low-input, pasture-based, and labor- and capital-extensive farming practices [1,3]. Despite the diversity of local contexts, these Mediterranean systems share common features. One of them is a specialization 
trend toward activities that require less labor, such as very extensive beef cattle $[2,13,14]$ or meat-lamb farming [7], rather than dairy activities. Management practices are kept as simple as possible, with low monitored herds and the abandonment of labor-intensive activities, such as the shepherding of livestock or fencing/hay-making [7,11,12]. Increases in herd size have also been observed [7,11], which can be explained by two factors: The availability of land and Common Agricultural Policy (CAP) subsidies. Indeed, an increase in herd size was initially allowed by the possibility of accessing new grazing areas-at low cost or even free of charge-when some rangeland became available after rural exodus and a consequent decrease in the number of farms [7,11]. In these systems, it is common that part of the land used by farmers does not belong to or is not rented by them. In this local context, there is a large amount of common land [12] or a number of informal arrangements with owners or with other users (when owners are absent, which is very common) [7]. The abundance of land, the low security of tenure, and the low expectations of profit in relation to certain extensive activities do not encourage maintenance investments in such areas $[14,15]$. Subsidies based on the number of animals and/or the area of rangeland, such as the CAP, also explain both the increase in herd size and the resurgence of interest for rangeland by farmers in E.U. countries [11]. Thus, in the E.U., these systems are usually characterized by low profitability (low costs but also low revenues) [7] and a high level of CAP subsidy dependency [3,12]. Difficult access to market infrastructures is often also observed [5] and, especially in dairy systems, on-farm and other small-scale processing is very important and generates the largest value-added [12]. Some consequences of this over-extensification can be observed in terms of vegetation cover and, subsequently, on landscape patterns. In fact, changes in both the type of livestock and the low monitoring of large, unfenced herds grazing on large areas have led to the disappearance of open spaces typical of extensive pasture. There has been a consequent loss of the traditional landscape that was maintained by goat- and sheep-breeding activities $[7,16]$. This evolution can increase the fire risk [17-21] and may also have an impact on functional biodiversity $[8,18,22,23]$. Moreover, the abandonment of agricultural management may also have an impact on the regulation of ecosystem services, such as pollination $[24,25]$ and water cycle regulation [26].

Through its evolution over the last few decades, the Common Agricultural Policy (CAP) has become one of the main drivers of the dual trend mentioned above and its associated impacts on landscapes $[1,3,5,27]$.

Many studies have outlined the need, but also the difficulty, of designing extensive practice support policies which are adaptable to landscape preservation objectives. This is particularly the case for livestock farming systems in less-favored areas (LFAs) in the Mediterranean [1,5,6,28,29]. Indeed, due to their specificities, these systems have low political weight at the European level, where support policies are mostly negotiated and designed [3,6,12]. More flexibility seems necessary, given the system's diversity [30,31]. Moreover, notions usually used in agricultural support policy design are not always relevant for such extensive systems in the Mediterranean. For instance, the notion of stocking rates (number of livestock units per ha) might be too simplistic for Mediterranean rangelands [11]. Indeed, it is often not relevant in large mountainous and forested areas, where herds are not geographically stable throughout the year and they often graze larger areas than those declared for CAP support [32].

Assessing the role of these payments is a complex issue, as it plays in contradictory directions, depending on the context [12]. Existing studies have reported that extensive practice support have been mitigated or limited, according to the considered LFA. For instance, Caraveli [1] reported evidence of increases in stocking densities in LFAs, which have sometimes led to overgrazing. Conversely, in line with Bartolomé et al. [33], Bernués et al. [18] indicated that grazing pressure was not able to stably maintain vegetation in the Mediterranean areas they analyzed.

Adequately designing and assessing the impacts of agricultural and agri-environmental policies is also difficult, due to the difficulty involved in obtaining reliable information about such farming systems. In fact, there is often a lack of official and reliable statistics about the figures and locations of farms $[1,4,12]$ and a lack of basic information about the extent and characteristics of grazing systems. Different sources sometimes show very different statistics [12] probably because data collection 
methodologies are adapted to more common farming systems, but not to extensive grazing ones. The latter might require a more qualitative approach for description [7], in a manner that would be informative for policy design and assessment.

In this paper, we focus on Castagniccia, a remote, less-favored Mediterranean area that presented many of the characteristics we have just mentioned, both in terms of over-extensification, livestock orientation, and management practices, as well as in terms of data availability and reliability.

The objectives of this paper are twofold: First, we want to assess the relationship between the type of livestock production and the change in land-cover over the longest period of available data. Our first hypothesis (H1) is that, given their respective morphological abilities, diet preference, and the way they are monitored, the landscape mosaic of forest and extensive pastures will be better maintained in sheep and goat grazing areas than in suckler-cows areas. Second, according to the obtained results, we aim to analyze the drivers of breeders' decisions. In fact, if one type of production is found to be better or more detrimental to the landscape, it is important to understand why some farmers opt for this type of production and not others, given that they are located in the same LFA and are subject to the same CAP incentives. Our second hypothesis (H2) is that suckler-cow breeding is more likely to be adopted as a complementary or main activity in farms in the context of labor scarcity and land abundance, while farms that are not in such a context, with the same CAP incentives, will opt for other production activities. To achieve these two objectives, we collected data on land-cover and farm characteristics for the early 1990s and 2012-2013 and analyzed their relationships.

The paper is organized as follows: First, we present our materials and methods by describing our study area (Section 2.1), as well as the data collection on land-cover and farms (Section 2.2). Then, we describe the strategy we adopted to analyze the relationship between livestock production and land-cover change (Section 2.3) and the choices of farmers (Section 2.3). Next, we present the results of the land-cover analysis and its relationship to farm characteristics (Section 3.1), as well as the results concerning the drivers of farmer choices (Section 3.2). Finally, we present the discussion and policy implications (Section 4).

\section{Materials and Methods}

\subsection{The Castagniccia Area}

Corsica is a mountainous island located in the French Mediterranean basin. Corsican agriculture mainly consists of small ruminant dairy farming and beef cattle ranching in the mountains and hills, with arboriculture and vine growing on the coastal plains. Castagniccia is a small area in the northeastern part of Corsica. It is a very rural region, far from the main urban areas in the middle of the northeastern Corsican mountains. This region has an extension of 45,015 ha (representing $5 \%$ of the total Corsican area) and includes 69 municipalities (Figure 1). The current landscape of Castagniccia was inherited from an ancient agricultural system based on terrace cultivation, chestnut growing, and small ruminant breeding [34]. This traditional system required a large amount of manpower and thus led to very high population density (more than 100 inhabitants $/ \mathrm{km}^{2}$ in the 19th century). The system collapsed at the beginning of the 20th century, leading to a decrease in population and to cultivation being substituted by very extensive breeding or land abandonment [35]. The permanent population of Castagniccia is now ageing, having a density of about 16 inhabitants per $\mathrm{km}^{2}$. About $16 \%$ of the adult population works in agriculture. In this region, as in many Mediterranean LFAs, steep slopes severely limit agricultural mechanization and labor-extensive suckler-cow breeding has developed since the 1980s [31,36]. In Castagniccia, this activity has sometimes also replaced traditional breeding (i.e., dairy ewe and dairy goat breeding). At present, agriculture in this area mainly consists of beef cattle farming for meat, small ruminant dairy farming (sheep and goats), pig farming (in abandoned chestnut orchards), and chestnut growing. Farms operate at a low level of capitalization on livestock production. Most farms-except those with only cows-process (i.e., into cured meats, cheese, chestnut flour, and pastry) and directly sell almost their entire production, which is the best way to improve 
value add [37]. Due to a lack of manpower, there have been few attempts to restore the chestnut orchards, which gave the name "Castagniccia" to the entire area.

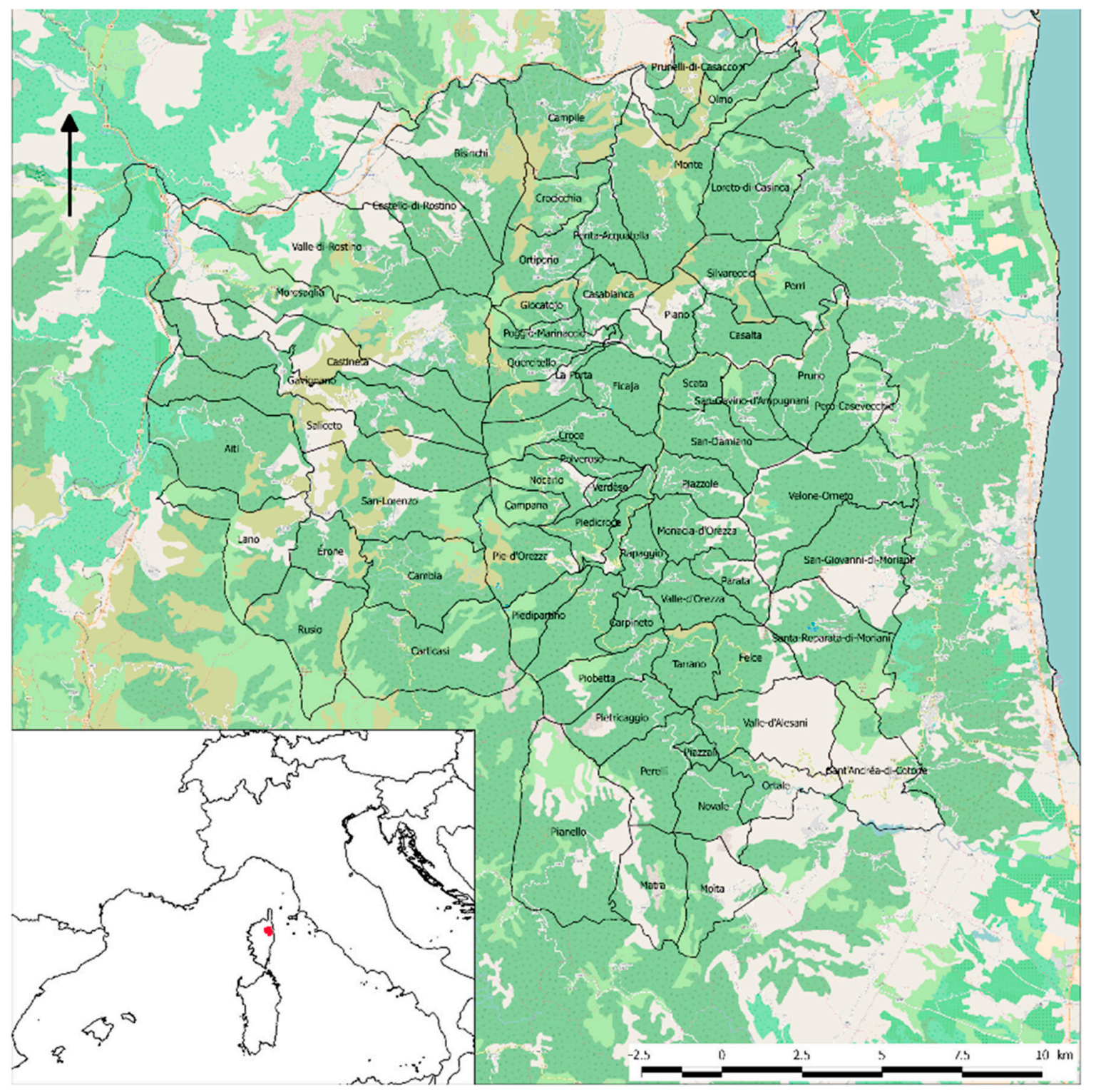

Figure 1. The Castagniccia area, Corsica.

\subsection{Data Collection}

As mentioned in the introduction, data availability and reliability are often an issue when studying Mediterranean extensive livestock farming. Land properties are small and dispersed, often in joint ownership between numerous landowners. Therefore, a farm often has multiple production sites with unfenced animals grazing around them, thanks to informal agreements between land users. Moreover, sources of information, such as the CAP's Land Parcel Identification System (LPIS) or the French Agricultural Census, do not always reflect the actual situation; especially concerning the number and size of the holdings. Indeed, some non-agricultural workers (usually relatives of farmers) are registered as individual farmers (heads of an agricultural holding), such that the large herds (and large associated grazing areas) of the actual farmers are administratively split into several small herds that get more subsidies than large ones. Therefore, identifying actual holdings is almost impossible without a deep knowledge of the field and the people living there. Consequently, combining heterogeneous sources 
of information is necessary, in order to ensure a comprehensive and reliable description of the study area. We used the following methods: (i) remote sensing techniques, in order to access land-cover change over the last few decades; (ii) field surveys of farmers; (iii) data on animals and areas declared by farmers corresponding to CAP subsidies.

\subsubsection{Land-Cover Data Collection and Processing}

We monitored vegetation cover changes for the years 1994 and 2012 by performing a remote sensing analysis. We acquired a series of satellite images on the two dates and processed them using specific classification methods, in order to obtain two detailed land-use maps. In particular, we used SPOT ${ }^{\circledR}$ imagery, which comes from a constellation of satellites combining optical and panchromatic sensors to acquire cartographic, agricultural, urban planning, and environmental management information. The SPOT images have a spatial resolution of $20 \mathrm{~m}$, allowing for the detection of mainland-cover on a landscape scale. The selected images were from August 1994 and June 2012. The software used for the classification was Multispec(C). We obtained land-cover maps showing six main different land-cover types: bare soil, grassland, low scrub (mainly cistus), high scrub (mainly heather), deciduous forest, and evergreen forest. The validation of these land-cover maps was performed. For 1994, we used Agripast-Sodeteg mapping of the pastoral areas of Corsica, dating from 1981 and updated in 1994, as a secondary source of information. For 2012, we validated the land-cover map through a field campaign, in which we acquired point co-ordinates and their land-cover types. We checked 60 field control points in the area, representing the different land-cover types. These points were used to calculate the classification performance. For 2012, we obtained an overall classification performance of $95.5 \%$. These results were also confirmed by experts during several meetings in the field, as well as through comparison with other geographical sources (e.g., Google Earth, aerial photographs) or cross-checking with land surveys.

In order to assess the changes in land-use between the two dates, we built a transition matrix comparing the initial and latter state in each pixel of the two land-use maps [38-40]. Considering our particular interest in pasture areas, we aggregated the two classes "deciduous forest" and "evergreen forest" under the general type "forest". In fact, breeding activities can prevent scrubland from turning into forest, through grazing. However, if vegetation turns to forest, grazing activities are unable to impact the kind of forest that appears—which is mainly determined by the soil—or impact the height of vegetation in already wooded areas; however, some animals, such as goats, can limit brushwood expansion in the undergrowth.

\subsubsection{Farm Data Collection}

The main sources of information about farm characteristics and management in the study area were a series of farm surveys and CAP declarations, field survey data, and a very detailed version of the 2012 Land Parcel Identification System (LPIS) database

Field surveys were conducted in spring of 2013, in order to obtain an exhaustive list of existing farms at the data collection time.

For each farm, the location of the production sites and their characteristics were collected (types of production, size of herds, number of workers, and seniority). Farmers were also asked about the historical development of the farm (owned by themselves or someone else) in the early 1990s (before 1994) and the types of production on the farm at this time. Participants were also asked for information on farms and production sites that no longer existed in the surroundings, in order to obtain the best possible picture of the situation in the early 1990s (Table 1). After cross-checking this information and comparison with LPIS data, we can say that the farm information for the early 2010 s is accurate and reliable. The information on early 1990s production sites (location and type of animal) was also considered reliable. Conversely, we believe that the information about the farms these production sites were used by in the past was far less accurate, as well as information regarding the changes in production at the farm level over time. 
Table 1. Number of sites of production and farms by type of production in early 1990s and 2012.

\begin{tabular}{|c|c|c|c|c|c|c|}
\hline $\begin{array}{c}\text { Type of } \\
\text { Production }\end{array}$ & $\begin{array}{l}\text { Number of } \\
\text { Sites of } \\
\text { Production } \\
\text { (Early 1990s) }\end{array}$ & $\begin{array}{l}\text { Number of } \\
\text { Sites of } \\
\text { Production } \\
\text { (2012) }\end{array}$ & $\begin{array}{c}\text { Change } \\
\text { 1990s-2012 }\end{array}$ & $\begin{array}{l}\text { Number of } \\
\text { Farms with } \\
\text { This Kind of } \\
\text { Production } \\
\text { (Early 1990s, } \\
\text { Approximate) }\end{array}$ & $\begin{array}{l}\text { Number of } \\
\text { Farms with } \\
\text { This Kind of } \\
\text { Production } \\
\text { (2012) }\end{array}$ & $\begin{array}{l}\text { Change } \\
\text { 1990s-2012 }\end{array}$ \\
\hline Pigs & 101 & 129 & $\nearrow$ & 73 & 81 & $\nearrow$ \\
\hline Sheep & 40 & 53 & $\nearrow$ & 23 & 21 & $\approx$ \\
\hline Goats & 75 & 119 & $\searrow$ & 34 & 36 & $\approx$ \\
\hline Suckler-cows & 95 & 123 & $\nearrow$ & 42 & 40 & $\approx$ \\
\hline Chestnut trees & 75 & 63 & $\searrow$ & 50 & 36 & $\searrow$ \\
\hline \multicolumn{4}{|c|}{ Total number of farms according to field surveys } & 184 & 177 & $\searrow$ \\
\hline
\end{tabular}

We also relied on the 2012 Land Parcel Identification System (LPIS) database. This database is generated each year by the E.U. "Agency for services and payments", on the basis of farmer's CAP declarations. It contains declared areas (i.e., the areas that farmers claim to be using and for which they can benefit from CAP subsidies). It also reports the subsidies that each farm receives, corresponding to various CAP measures. CAP measures are divided into two pillars: In the first pillar, animal premiums and Single Farm Payments (SFPs) are the most relevant for the study area. Animal premiums depend on the type and number of animals. SFPs (introduced by the 2002 CAP reform) are granted to farmers whose farm is of a certain size and who are decoupled (i.e., they do not depend on the production type and volume). In France, they are calculated for every farm based on historical references. In the second pillar, "rural development", the only relevant payment to consider in the study area is the less-favored area support scheme. LFA support is granted per hectare used to feed animals, up to a ceiling of 50 ha, and its amount depends on certain stocking rate conditions (see Table 2). To reconstitute actual holdings, we needed a version of the database which is more detailed than the publicly available one. We only had access to the detailed version for the year 2012.

Table 2. Main CAP subsidies in Castagniccia, 2012.

\begin{tabular}{|c|c|c|c|}
\hline Subsidies & Type of Subsidies & Amounts 2012 (€/Year) & Source \\
\hline $\begin{array}{l}\text { Animal premiums } \\
\text { for suckler-cows }\end{array}$ & First pillar, coupled & $\begin{array}{l}\text { EUR } 200 \text { per suckler-cow up to } 40 \text { cows, } \\
\text { EUR } 175.85 \text { per suckler cow over } 40 \text { cows. } \\
\text { Having at least } 3 \text { suckler-cows is required. }\end{array}$ & \multirow{3}{*}{$\begin{array}{l}\text { Direct communication } \\
\text { from local agriculture } \\
\text { and forestry } \\
\text { administration. }\end{array}$} \\
\hline $\begin{array}{l}\text { Animal premiums } \\
\text { for dairy goats }\end{array}$ & First pillar, coupled & $\begin{array}{l}\text { EUR } 8.68 \text { per adult dairy goat (EUR }+3 \text { per } \\
\text { adult dairy goat under specific conditions), if at } \\
\text { least } 25 \text { adult dairy goats. No more than } \\
400 \text { adult dairy goats can receive the premium. }\end{array}$ & \\
\hline $\begin{array}{l}\text { Animal premiums } \\
\text { for dairy ewes }\end{array}$ & First pillar, coupled & $\begin{array}{l}\text { EUR } 21 \text { per adult dairy ewe (EUR }+3.22 \text { per } \\
\text { adult dairy ewe under specific conditions), if at } \\
\text { least } 50 \text { adult dairy ewes. }\end{array}$ & \\
\hline SFPs & $\begin{array}{l}\text { First pillar, } \\
\text { decoupled }\end{array}$ & $\begin{array}{l}\text { In our study area (for farms receiving SFP): } \\
\text { Mean value } 219 € / \text { ha, Median Value: } 93 € / \text { ha. } \\
\text { Support requires very basic } \\
\text { agro-environmental maintenance. }\end{array}$ & $\begin{array}{l}\text { Our data: CAP parcel } \\
\text { register, } 2012 \text { for } \\
\text { Castagniccia. }\end{array}$ \\
\hline $\begin{array}{l}\text { LFA subsidies (for } \\
\left.\text { animal feed areas* }{ }^{*}\right) \\
\text { (EUR) }\end{array}$ & Second pillar & $\begin{array}{l}274 \text { EUR/ha under } 25 \text { ha, } 183 \text { EUR/ha up to } \\
50 \text { ha of area used to feed animals; premium } \\
\text { increased by } 30 \% \text { for the first } 25 \text { ha if } 50 \% \text { of } \\
\text { livestock units (LSU) are goats and/or sheep. } \\
\text { These amounts are granted for areas where the } \\
\text { stocking rate is from } 0.8 \text { to } 1.2 \text { LSU per } \\
\text { declared ha. LFA support per ha decreases } \\
\text { outside that range. }\end{array}$ & $\begin{array}{l}\text { Direct communication } \\
\text { from local agriculture } \\
\text { and forestry } \\
\text { administration. }\end{array}$ \\
\hline
\end{tabular}




\subsection{Assessing the Relationship between Livestock and Land-Cover Changes (H1)}

In this phase, we aimed to assess if land-cover in 1994 and 2012 and land-cover change between these two dates were related to the livestock production type. Around each production site, the area in which land cover is likely to be impacted by the presence of animals depends on the physical characteristics of the animals (i.e., mobility and diet preferences leading to grazing a rather large or small area) and on the livestock management practice (e.g., parking, shepherding). According to the animal behavior and management of the Corsican herds reported in the literature and expert knowledge [20], we drew different buffers around the 1990s and 2012 production sites: small buffers around pig production sites (15 ha), medium-sized buffers around sheep production sites (70 ha), and large buffers around goat and suckler-cow production sites (150 ha). After the first assessment, we did not consider pig production sites, as this livestock type does not really have an effect on vegetation management and is completely different from the breeding characteristics of the other livestock typologies. Figure 2 shows these buffers around the 2012 production sites.

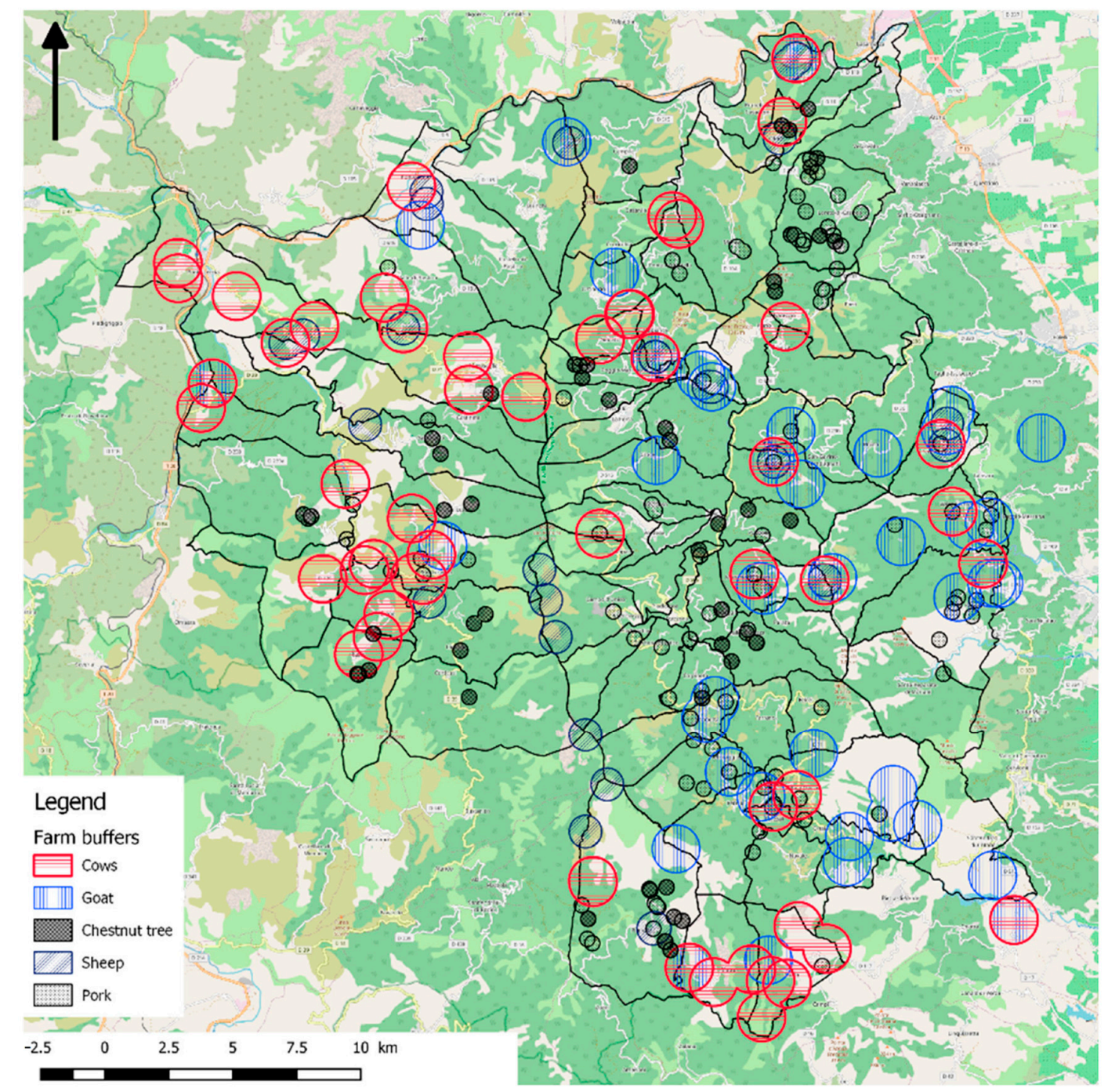

Figure 2. Production sites and their surrounding buffer zones (2012).

Then, we analyzed land-cover and land-cover change for the following:

- The whole study area (WA); 
- The area that was neither impacted by livestock breeding activities in the early 1990s nor in 2012, according to our data (hereafter NI area-i.e., "non-impacted area"), as a benchmark to assess the impact of livestock breeding activities;

- The areas that were assumed to have been impacted only by one kind of breeding activity over the period, in order to analyze the animal-specific impacts.

According to the literature and expert knowledge about livestock management practices in this area, we expected a stronger impact of goats and sheep, in terms of limitation of vegetation growth. Indeed, dairy sheep herds need to be located in human-maintained low-vegetation areas, while the behavior of goats is well-known to limit scrub encroachment and brushwood expansion into the undergrowth [41]. Both kinds of herds need to be rather closely monitored, such that daily milking is possible and productive. On the contrary, suckler-cow herds are barely monitored in this region and research has not been conducted extensively. This leads very low actual stocking densities. Given this density and due to the physical capabilities and diet preferences, we believe that cow breeding, as performed in the region, cannot contribute to decreasing the level of vegetation and, thus, prevent afforestation.

\subsection{Analyzing Production Decision Drivers (H2)}

In the particular context of Corsica, as farms operate at a low level of capitalization, the main farm inputs include labor, available land, and livestock. Permanent labor can be approximated as a fixed factor as, when there are several permanent workers on a farm, they are most of the time associate farmers, not employees. Concerning land, we know the declared area; however, this area might be smaller (and not always located exactly in the same place) than the actual area used by non-fenced and non-stationary livestock to graze. However, the quantity of land either declared or used by a farm depends on the local context. In fact, when a farmer needs land (for instance, to comply with required stocking densities to get LFA subsidies), they must arrange with other farmers to use and declare land that is usable and eligible (i.e., covered by low-vegetation), but which is not already used and declared. Most of the time, these areas are the ones that have been abandoned by former farms $[7,11]$, where forest has not had the time to grow and the area is covered by low scrub. Given that all farms are subject to the same CAP incentives and that the animal-specific level of capitalization is low, the choice of the types of animals (goats, sheep, pigs, cows) essentially depends on the compatibility between the land and labor requirements of those animals and the availability of land and labor at the farm level. Consequently, we focused on the role of these labor and land characteristics on the production choice decision.

Our hypothesis is that suckler-cow breeding is more likely to be adopted as a complementary or main activity in farms in the context of labor scarcity and land abundance, whereas farms that are not in such a context, under the same CAP incentives, will opt for other productions. Indeed, suckler-cow breeding requires less labor than dairy goat or sheep breeding, such that this activity may interest farms with few workers. However, the value-adding that can be generated by the extensive suckler-cow breeding is very low. In this context, the main incentives to breed suckler-cows in the area seem to be related to CAP subsidies [3,30]. However, to get the maximum subsidies, farms need to declare larger areas of land for cow breeding, than for sheep- or goat-breeding. To test this hypothesis, we estimated a multinomial logit model, in which the dependent variable "Ranch" is a categorization of farms: those with only-suckler cows, those with cows among other productions, and those without cows. To consider the eligible/usable land availability, we considered the following as explanatory variables (all the variables are resumed in Table 3):

- The variation in production site density around the farm (proxy of land abandonment) and the percentage of low scrubland area around the production sites (proxy of farm's access to areas that are usable without human intervention, especially by cows) and the area declared by farmers in 2012 (proxy of farm's access to eligible land); 
- The number of full-time workers in the farm and, as a proxy for opportunity cost of labor, the demographic characteristics of the municipality where the holding of the farm is located and those of the surrounding municipalities. Indeed, proximity to a relatively populated municipality might increase the relative scarcity of labor through a higher opportunity cost, while remoteness might increase its absolute scarcity.

Table 3. Main characteristics of the model variables.

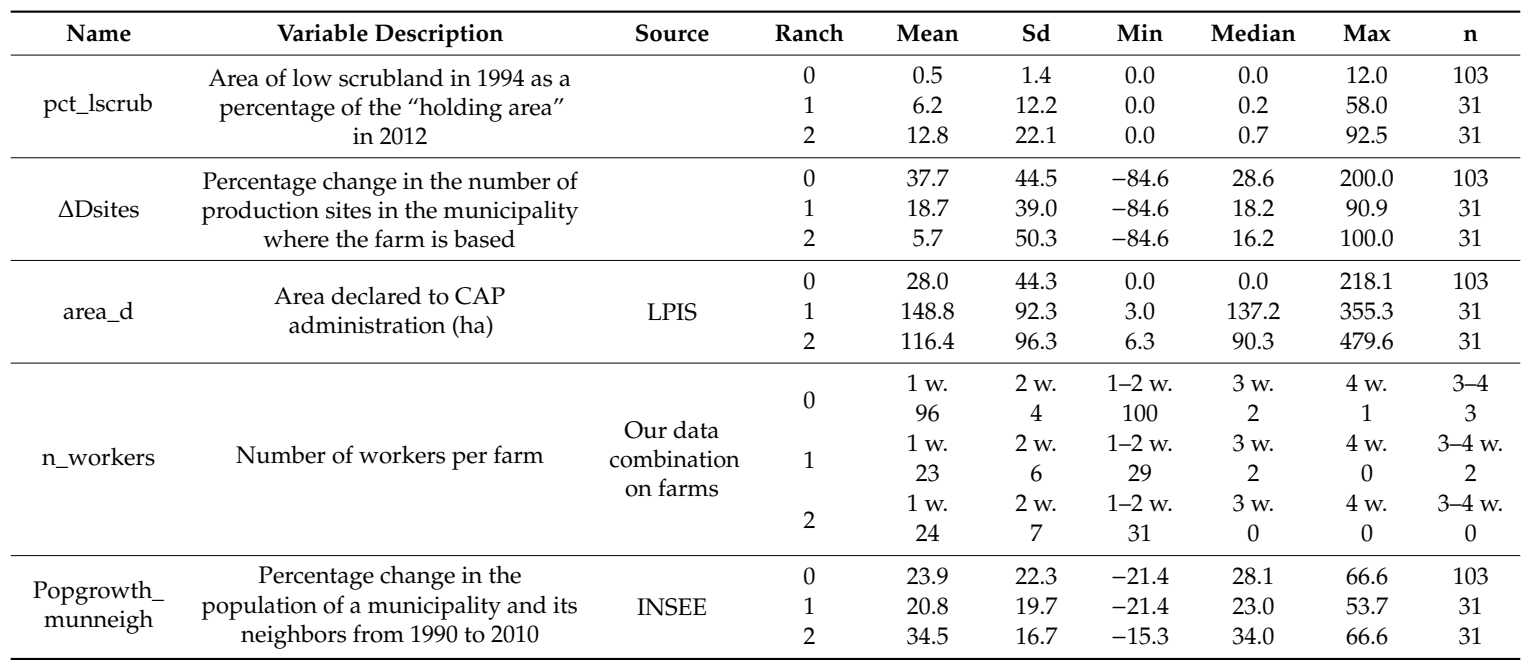

We checked for the absence of outliers and collinearity. We also checked for the independence of irrelevant alternatives (Hausman test), to ensure that an ordered multinomial logit might not have been more suitable. We performed a Wald test to check if the three alternatives (no suckler-cow $=0$; suckler-cows among other productions $=1$; suckler-cows only $=2$ ) were actually different (otherwise, a binomial model might have been more appropriate).

\section{Results}

\subsection{Vegetation Cover Changes and Correlation with the Livestock Type}

Figure 3 shows the percentage of each type of land-cover in 1994 and 2012 for the different types of areas. The very small differences between the whole (WA) and the "non-impacted" (NI) areas can be explained by the fact that the NI area represents $72 \%$ of the WA area. In 1994, the percentage of forest was the highest for the goat-only areas, while the lowest was for the sheep-only area (in line with empirical field knowledge).

The change in area of each land-cover from 1994 to 2012 indicated a decrease in bare-soil, grassland, and high scrubland areas, with an increase in low scrubland and forest areas for WA, NI, sheep- and cow-only categories. There was also a general increase in forested areas concerning each kind of area, except for goat-only areas. For the goat-only areas, $35 \%$ of the area impacted was no longer forested in 2012; however, this was probably due to fire, rather than grazing (see below).

In order to better understand the underlying dynamics, we analyzed the transition matrix. Table 4 shows the dynamics for the whole area. 


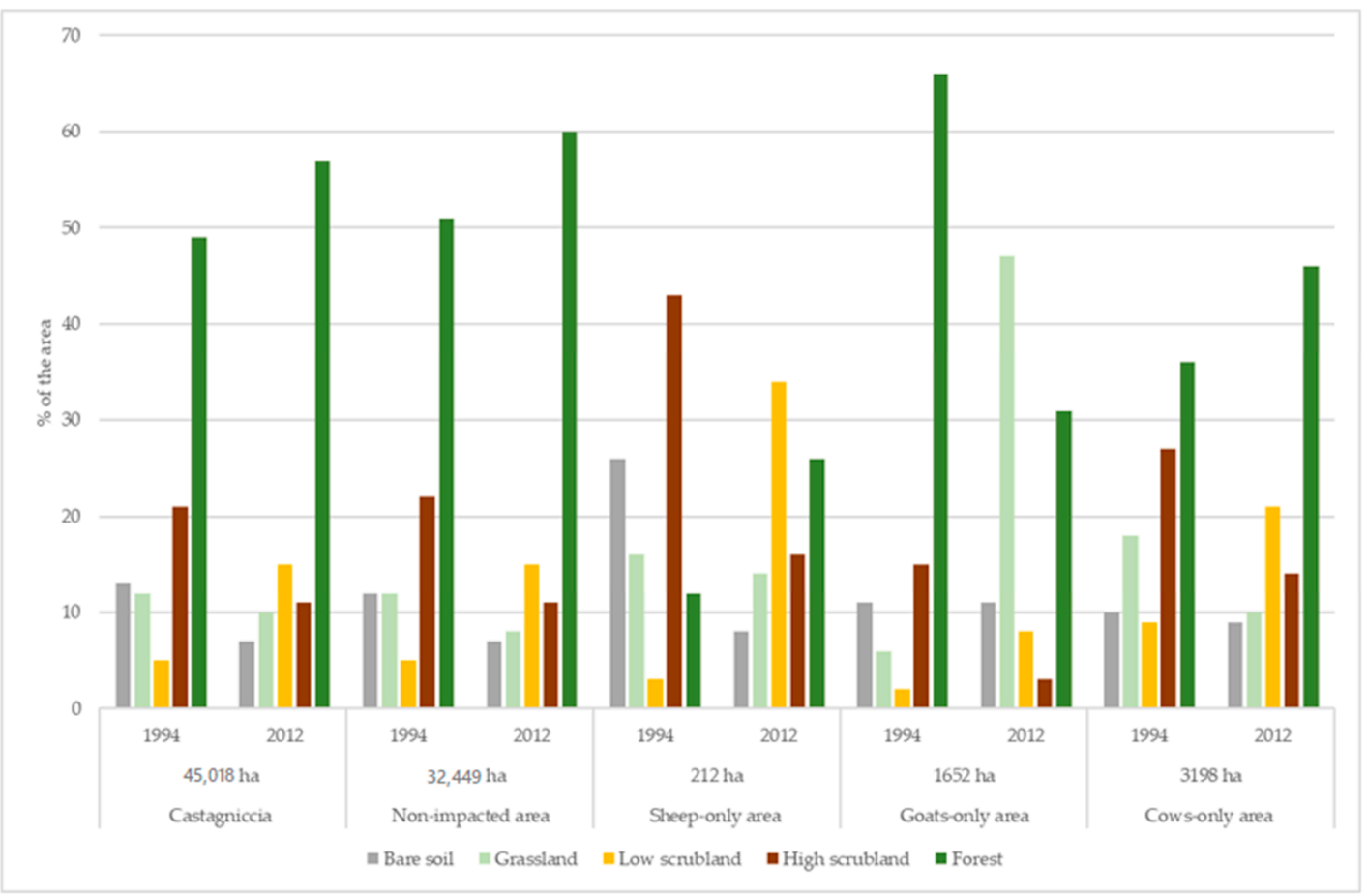

Figure 3. Percentage of each land-use type on the different buffer zones on 1994 and 2012.

Table 4. Transition matrix and associated calculations for the whole area.

\begin{tabular}{cccccccc}
\hline $\mathbf{1 9 9 4}$ & $\begin{array}{c}\text { Bare } \\
\text { Soil in }\end{array}$ & Grassland & $\begin{array}{c}\text { Low } \\
\text { Scrublands }\end{array}$ & $\begin{array}{c}\text { High } \\
\text { Scrublands }\end{array}$ & Forest & Total & $\begin{array}{c}\text { \% of the Area } \\
\text { Covered in 2012 }\end{array}$ \\
\hline Bare soil & 1032 & 486 & 667 & 799 & 147 & 3132 & $7.0 \%$ \\
Grassland & 2194 & 297 & 175 & 430 & 1298 & 4395 & $9.8 \%$ \\
Low scrubland & 1105 & 1997 & 713 & 2371 & 616 & 6801 & $15.1 \%$ \\
High scrubland & 264 & 1558 & 418 & 2116 & 527 & 4884 & $10.8 \%$ \\
Forest & 1215 & 1185 & 294 & 3563 & 19,549 & 25,807 & $57.3 \%$ \\
Total & 5811 & 5524 & 2266 & 9280 & 22,137 & 45,018 & $100.0 \%$ \\
\% of the total area & $12.9 \%$ & $12.3 \%$ & $5.0 \%$ & $20.6 \%$ & $49.2 \%$ & $100.0 \%$ & \\
covered in 1994 & & & & & & &
\end{tabular}

According to local knowledge, deforestation had not occurred due to an increase in livestock pressure; thus, we did not consider changes in forested areas from 1994 to 2012 as being the result of animal impact. Indeed, the change from forest to a lower level of vegetation seems mainly to be the consequence of fires-which are frequent in this area-and could be an indirect land-cover change induced by livestock management practices. In fact, a reduction in the grazing effect and the consequent non-controlled and non-managed reforestation can increase the risk of wildfire. However, considering this as a secondary effect, we did not insert this change into our analysis. Therefore, we rather focused on changes that occurred over areas that were "low-covered" (i.e., bare soil, grassland, low scrubland, and high scrubland) in 1994. We identified three main types of changes: first class (1), "favorable" transitions included a decrease in the level of vegetation, such as transitions from low scrub to grass, from heather to grass or cistus, and the maintenance of the same level of vegetation (for grassland and low and high scrubland). These transitions may be a consequence of the maintenance of agricultural activities with an adapted level of extensification for the maintenance of landscape mosaic. We also included the transition from bare soil to grassland in these changes. The second class (2), "unfavorable" transitions, included increases in vegetation cover, such as transitions from grassland to high scrubland or forest, or from low and high scrubland to forest. This transition may have been the consequence of over-extensification or the abandonment of agricultural activities. We also included 
the appearance of soil that was no longer protected from degradation (e.g., erosion) by vegetation cover due to these changes; that is, transitions from grassland or low or high scrubland to bare soil. In fact, these transitions may be the consequence of locally higher "stocking densities" (as observed, for instance, around some feeding points). Finally, the third class (3), "intermediate" transitions, included the other transitions that were considered intermediate in terms of open-space/extensive pasture preservation, such as the changes from bare soil and grassland to low scrubland and from low to high scrubland. Areas that remained bare soil from 1994 to 2012 (1032 ha) were not considered in these three categories of changes, as we assumed that these areas were either artificialized areas (sealed soils, buildings) or rocky areas. Figure 3 shows the percentage obtained for each land change class in the study area. Furthermore, we detail the transitions found for each category of the 1994 vegetation cover and each mode of livestock production in Figures 4 and 5.

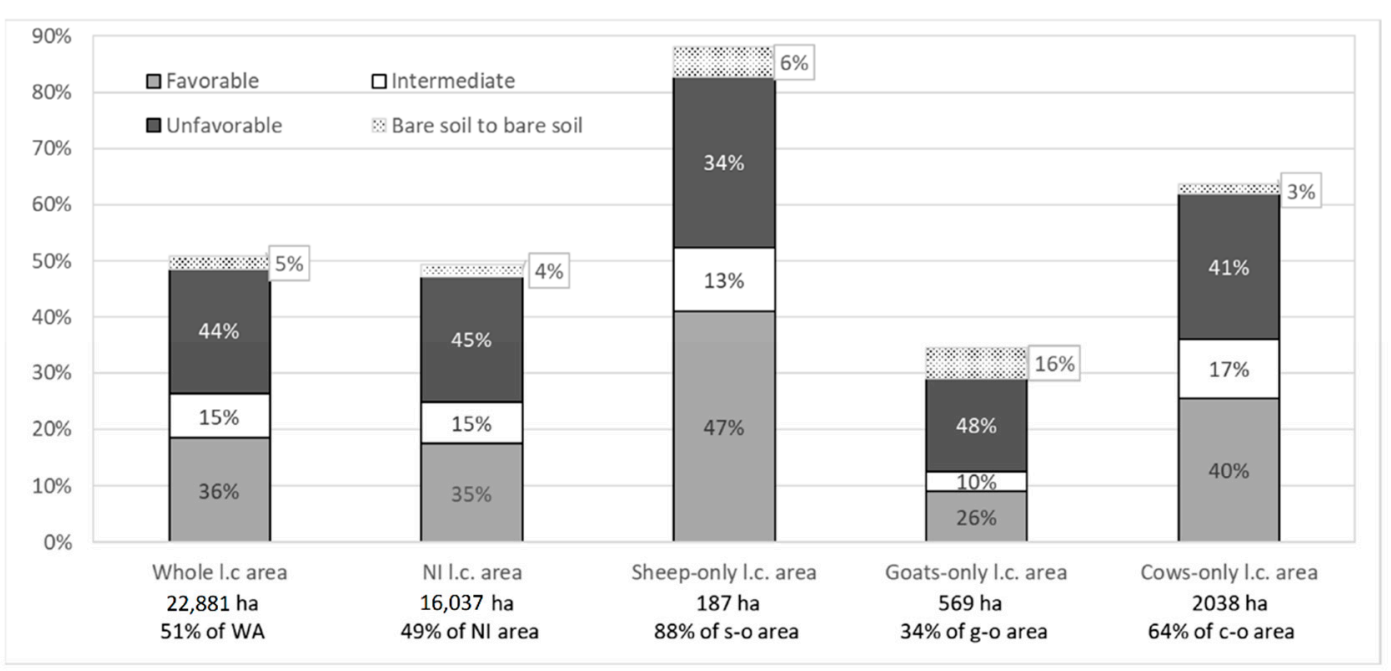

Figure 4. Importance of the different kinds of transitions for the 1994 "low-covered" animal-specific areas. Each bar describes the change observed from 1994 to 2012 for a given area. The total low-covered area (ha) of each category is mentioned below each bar.

The land-cover analysis shows that, in 1994, goats were mainly located in forested areas, while sheep and cows were located in areas with lower cover, corresponding to their preferences in terms of grazing areas, according to expert opinion. Transitions observed in the 1994 low-covered area (Figure 4) showed that sheep-only areas had the highest percentage of class 1 transitions and the lowest percentage of class 2 ones. Cow-only areas showed percentages close to, but slightly better than, those observed for the non-impacted area, suggesting the negligible (or, at least, weak) impact of such production on low vegetation growth. Sheep and goats performed better on grassland (Figure 5), followed by cows. Concerning low scrubland, sheep followed by cows performed better than others, while goats had a similar impact on vegetation to that observed in the WA and NI areas. Finally, the goat-only areas had the worst impact on high scrubland, while sheep breeding performed the best. 


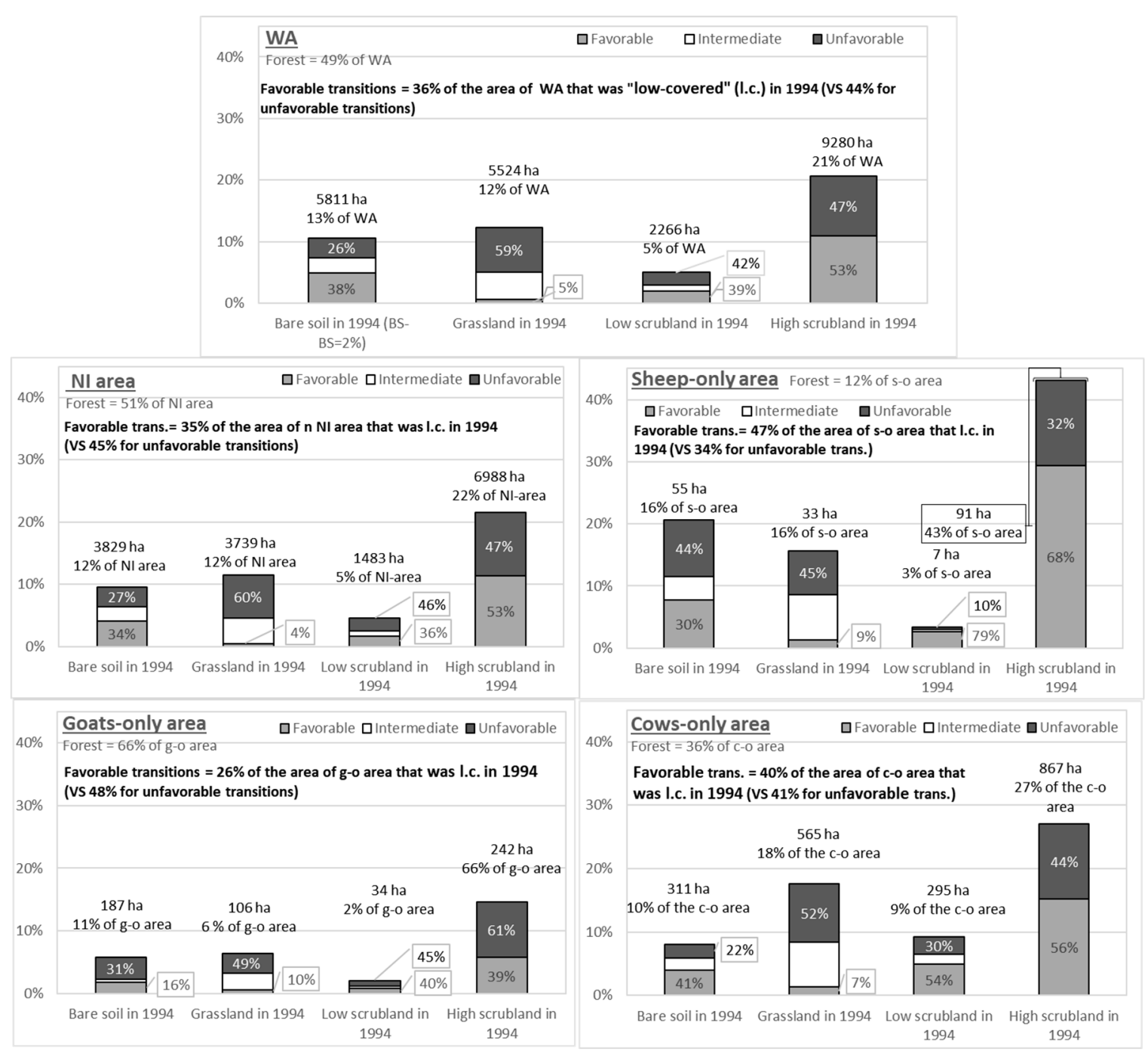

Figure 5. Each graph describes the change observed from 1994 to 2012 for a given category of area (WA, NI area, or "animal"-only areas). The total area of each of 1994's land-cover is mentioned above each bar (as well the percentage of the total area of each category it represents).

\subsection{The Contribution of CAP Premiums to Farm Income and Drivers of Farmer Choices}

Table 5 shows the results of the multinomial logit model. The $p$-values of the Hausman test for IIA were above 0.5 , which means that an ordered multinomial logit was not necessary. As we found a low level of significance for the difference between alternatives 1 and $2(0.1<p$-value $<0.05)$, we also performed a binomial logit that estimated the choice between having cows or not (Table 6 ). The binomial logit model showed similar effects to the multinomial ones. 
Table 5. Estimation results of the multinomial logit model.

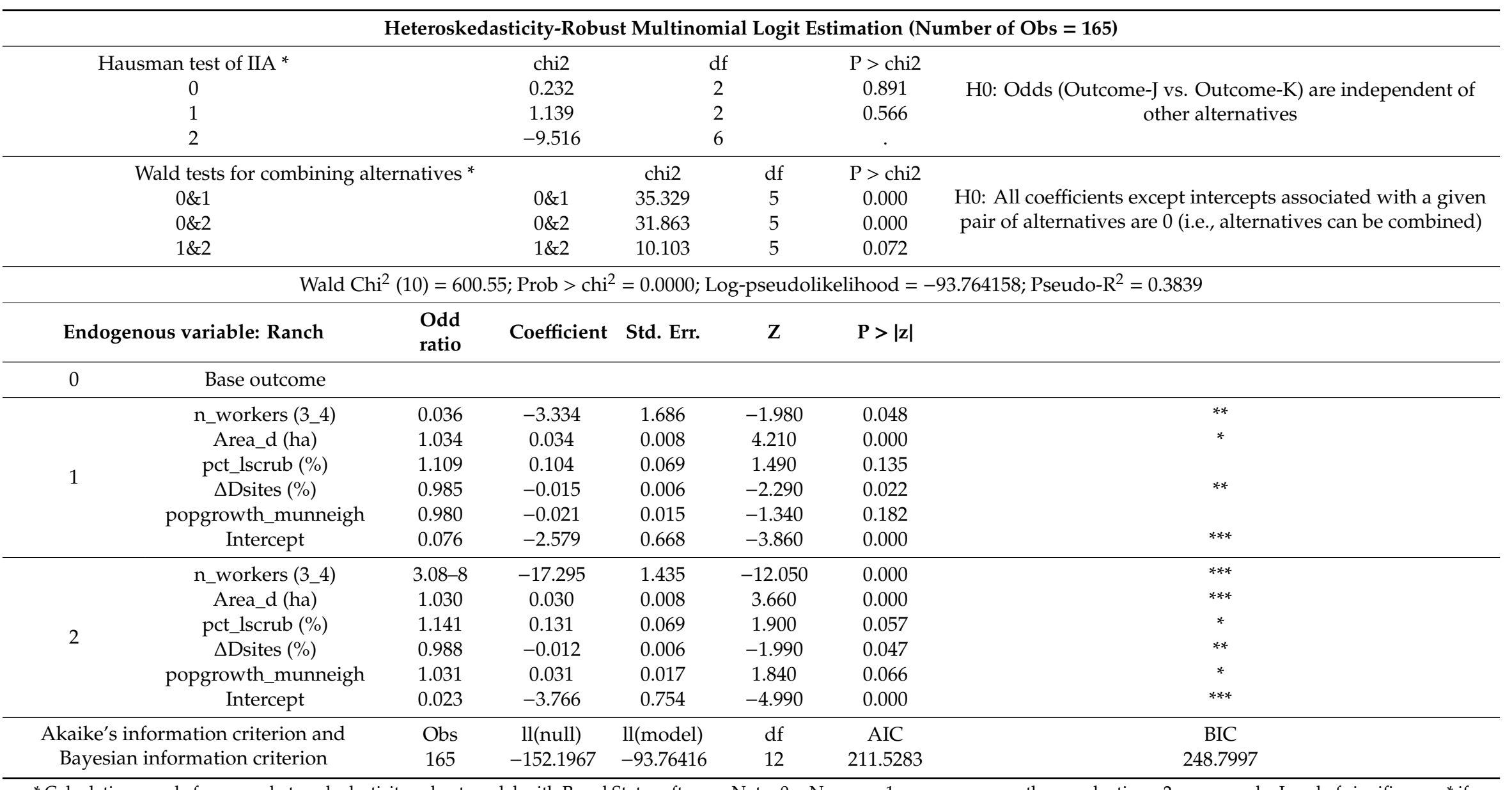

* Calculations made from non-heteroskedasticity-robust model with $\mathrm{R}$ and Stata software. Note: $0=$ No cows, $1=$ cows among other productions, $2=$ cows only. Level of significance: ${ }^{*}$ if

$p<0.1$ (significant at 10\% level); ${ }^{* *}$ if $p<0.05$ (significant at $5 \%$ level); ${ }^{* * *}$ if $p<0.01$ (significant at $1 \%$ level). 
Table 6. Estimation results of the selected binomial logit model.

\begin{tabular}{|c|c|c|c|c|c|c|c|}
\hline \multicolumn{8}{|c|}{ Heteroskedasticity-Robust Binomial Logit Estimation (Number of Obs = 165) } \\
\hline \multicolumn{8}{|c|}{ Wald $\operatorname{chi}^{2}(5)=26.61 ;$ Prob $>$ chi $^{2}=0.0001 ;$ Pseudo- $\mathrm{R}^{2}=0.4621 ;$ Log-pseudolikelihood $=-58.75$} \\
\hline \multirow{2}{*}{\multicolumn{2}{|c|}{ Variance inflation factor * }} & n_workers & Area_d & pct_lscrub & $\Delta \operatorname{Dexp}$ & \multirow{2}{*}{\multicolumn{2}{|c|}{$\begin{array}{c}\text { popgrowth_munneigh } \\
1.122359\end{array}$}} \\
\hline & & 1.404422 & 1.513635 & 1.029434 & 1.281444 & & \\
\hline \multirow{2}{*}{ No Studentized residuals with Bonferonni $p<0.05$} & \multirow{2}{*}{ Largest |rstudent|: } & & rstudent & \multicolumn{2}{|c|}{ Unadjusted $p$-value } & \multicolumn{2}{|c|}{ Bonferonni $\mathrm{p}$} \\
\hline & & 12 & -3.016446 & \multicolumn{2}{|c|}{0.0025576} & \multicolumn{2}{|c|}{0.422} \\
\hline Ranch $=$ having suckler $(1)$ cows or not $(0)$ & Odd Ratio & Coef. & Std.Err & $\mathrm{Z}$ & $\mathrm{P}>|\mathrm{z}|$ & \multicolumn{2}{|c|}{$* * *$} \\
\hline Area_d & 1.032 & 0.031 & 0.008 & 4.020 & 0.000 & \multicolumn{2}{|c|}{$* * *$} \\
\hline pct_lscrub & 1.119 & 0.113 & 0.063 & 1.790 & 0.074 & \multicolumn{2}{|c|}{ * } \\
\hline$\Delta$ Dsites & 0.987 & -0.013 & 0.005 & -2.410 & 0.016 & \multicolumn{2}{|c|}{ ** } \\
\hline popgrowth_munneigh & 1.004 & 0.004 & 0.013 & 0.300 & 0.767 & \multirow{2}{*}{\multicolumn{2}{|c|}{$* * *$}} \\
\hline Intercept & 0.101 & -2.293 & 0.618 & -3.710 & 0.000 & & \\
\hline \multicolumn{8}{|c|}{ Note: 0 -failures; 1 -success completely determined. } \\
\hline \multirow{2}{*}{\multicolumn{2}{|c|}{ Akaike's information criterion and Bayesian information criterion }} & Obs & ll(null) & ll(model) & Df & AIC & $\mathrm{BIC}$ \\
\hline & & 165 & -109.2216 & -58.75505 & 6 & 129.5101 & 148.1458 \\
\hline
\end{tabular}

${ }^{*}$ Calculations made from non-heteroskedasticity-robust model with R and Stata software. ${ }^{*} p<0.1 ;{ }^{* *} p<0.05 ;{ }^{* * *} p<0.01$ 
Concerning the overall performance, the multinomial logit had a pseudo- $\mathrm{R}^{2}$ of 0.38 (which is relatively high for such a model) [42] and the binomial logit had a pseudo- $\mathrm{R}^{2}$ of 0.46 . In both models, all variables were significant at least at the $10 \%$ level ( $p$-value $<0.1$ ), except for the percentage of population growth around the headquarters of the holding (popgrowth_munneigh) in the binomial logit.

A higher ( 3 to 4 ) number of workers had a significant and negative effect on the probability of having suckler-cows (in combination with other productions or alone), rather than not having them. These results confirm our hypothesis: When labor is abundant, income comes from more labor-intensive activities. When labor is scarcer, suckler-cow breeding becomes an interesting way to complement agricultural income or is the only way to have an income.

As expected, the declared area had a positive and very significant effect on the probability of having cows, as a spatial pre-condition of a sufficient minimum size for cow breeding farms. In fact, each model highlighted that any extra declared hectare multiplies the likelihood of having cows, rather than not having cows, by about 1.03 (or an increase of 3\%). This hypothesis was also confirmed by the $\mathrm{Chi}^{2}$ test of independence between the two variables "Ranch" (having or not cows) and the number of workers, which indicated that the area was a great predictor. With regard to the initial land-cover classes that can favor the choice of suckler-cow production, the largest effects were observed when considering the percentage of low scrubland. This effect was positive and significant on the probability of having cows alone, rather than no cows. The percentage of change in the number of sites in the municipality had a negative and significant effect: when the density of sites increased, choosing to breed suckler-cows was less likely. As for the declared area, the magnitude of the effect was larger when cows were present alongside other livestock types than when cows were the only production. This is because, in order to have cows, farms need additional land to that needed by other production methods. These effects validate our hypothesis of suckler production developing on abandoned land, which is usually no longer grassland, but still has low land-cover, due to its relatively recent abandonment. Finally, increases in the municipal population and in the population of neighboring municipalities had positive and significant effects on the probability that farms located in this municipality will only have cows. This suggests that, in the most demographically dynamic areas, the higher opportunity cost (due to non-farm better-paid job opportunities, which might be more numerous) leads to farmers opting for this labor-extensive production method.

\section{Discussion}

The first hypothesis of this work was that maintaining extensive pasture land-cover would be observed in sheep and goat grazing areas rather than in suckler-cow ones, given their respective morphological abilities, diet preference, and the way that they are monitored. According to the land-cover analysis, this hypothesis was partially verified: On the one hand, sheep-breeding is generally associated with extensive pastureland-cover; however, this is not the case for goat-breeding. In general, goats tend to select a higher proportion of shrubs than other herbivore species [41] but, in this case, we can attribute the unexpected low performance of goat-breeding to the insufficiency of the actual stocking densities in impacting the vegetation growth and/or to the non-visibility of this impact due to the methodology we used. A similar effect of herd size on vegetation control, particularly for goat grazing, has been reported in other previous studies [42,43]. On the other hand, suckler-cow breeding had a very limited-almost negligible-impact on vegetation growth. Similar studies developed in other agro-environmental regions [44] have obtained comparable results. For example, [45] showed that the reduction in goat and sheep grazing in northern Spain contributed to an increase in wood and shrub vegetation, consequently affecting fire risk. In the Mediterranean area, contrasting dynamics have been observed. In some cases, strong grazing intensification substituting for the traditional agroforestry and pastoral systems have caused land degradation [46,47]. In other cases, extensive cattle grazing did not really preserve the existing open landscapes, with remarkable increases in woody and shrub vegetation [48-50], as was the case in our work. This limited impact of extensive pastures on preserving the open landscape from abandonment and reforestation questions the relevance of 
the landscape management rationale of subsidies for suckler-cow breeding. Thus, compliance with the requirements of actual management and stocking densities for cows and goat breeding and/or compliance with remote (for cows) and on-field (for goats) vegetation growth conditions would be recommended [51,52].

Our second hypothesis was that suckler-cow breeding would be more likely to be adopted as a complementary or main activity in farms in the context of labor scarcity and land abundance. On the contrary, farms that were not in such a context, under the same CAP incentives, would rather opt for other production methods (leading to a less CAP subsidy-dependent income). The multinomial and binomial logit regressions showed that this hypothesis was verified. Labor scarcity (low number of workers, high labor opportunity cost) and the availability of low-cover (both suckler-cow "usable" and "CAP-declarable") land significantly increased the probability of having suckler-cows (in combination with other production methods or alone). The impact of land availability and field area on bovine systems has already been demonstrated in previous studies [53,54]. In accordance with our results, Gourdouvelis et al. [55] pointed out that high pasture availability, in terms of land, implies a lower reliance on external subsidies in a Mediterranean internal area of Greece. Complementarily, we highlighted the importance of CAP subsidies in the income of farms with suckler-cows. In terms of policy recommendations, our results confirm the need for a more effective targeting of areas eligible for CAP premiums, as underlined by Pe'er et al. [56]. This could be achieved, for instance (as advocated by Cocca et al. [5] for the Italian Alps), according to criteria such as altitude or targeted animal production practices. Subsidies should be redesigned, such that they (i) are more favorable to production that has the most positive impact on vegetation, such as sheep (or goats if actual minimal stocking rates or equivalent criteria are imposed); (ii) ensure that the decrease in certain premiums does not lead to even less maintenance of the landscape. Thus, subsidies should only be given if they encourage effective maintenance. Another option is to use biomass characteristics or locations that have the highest ecological/patrimonial/fire risk prevention interests. In fact, the real stocking rates might be different from theoretical ones and difficult to monitor; thus, the eligibility conditions should rather rely on biomass state or change.

A reformed CAP was implemented in 2014; that is, just after the end of our study period. Although trade-offs had to be made, in order to ensure political acceptance, the 2014 changes were in line with our observations, regarding the inadequacy of the requirements of stocking rates in such very extensive areas and the need for more suitable conditions regarding biomass. Indeed, with the 2014-2020 version of the CAP, as implemented in our study area, stocking density is no longer considered. In addition, an even wider range of areas (in terms of biomass characteristics) can now benefit from subsidies. However, there is a stronger scaling factor in the amount granted according to biomass characteristics, as associated with stricter field controls.

\section{Conclusions}

In this paper, we focused on Castagniccia, a remote, less-favored Mediterranean area. This area presents many of the characteristics common to extensive Mediterranean livestock breeding areas, both in terms of over-extensification, livestock orientation, and management practices (with their associated socio-environmental and policy design issues), and in terms of data availability and reliability. These characteristics necessitated the adoption of a multidisciplinary approach, which combined qualitative and quantitative methodologies to assess: (i) the relationship between the type of livestock production and the change in land-cover; (ii) the drivers of farmer decisions concerning the types of livestock they breed.

Our results show that Mediterranean ranching systems use agricultural land abandonment to maximize personal income, together with CAP premiums (despite low agricultural profits). Consequently, in areas with a low farm density, the objective of the CAP premiums to maintain agricultural landscapes does not seem to be achievable under the current levels of human and livestock pressure. A new CAP reform is currently being discussed for implementation in 2021. In fact, 
the European Commission released legislative proposals in June 2018 [57]. Aside from a likely decrease in the total CAP budget and a willingness to pursue decoupling and convergence in the amount of direct payments (CAPeye, 2018), these proposals would provide Member States with more flexibility in deciding on financial allocations (including transfers between pillars). Member States would be more able to develop tailor-made programs that most effectively address their farmers needs and those of the rural communities. These programs are subject to EC approval and the results will be monitored closely. Supporting small- and medium-sized farms and protecting the environment are also among the priorities of the proposal [58]. Nonetheless, these proposals are quite controversial [59] and, in our opinion, are still too general to allow us to make relevant comments regarding our research focus.

Author Contributions: L.D.: conceptualization, formal analysis, methodology, writing-original draft; M.D.: conceptualization, writing - original draft, visualization, writing - review and editing; J.C.P.: conceptualization, funding acquisition, project administration; C.N.: conceptualization, methodology, supervision; M.M.: data curation, visualization; L.L.: investigation, data collecting; P.S.: investigation, data collecting. All authors have read and agreed to the published version of the manuscript.

Funding: This research was funded by the European Commission through the Seventh Framework Programme, project CLAIM Supporting the role of the Common agricultural policy in LAndscape valorisation: Improving the knowledge base of the contribution of landscape Management to the rural economy.

Conflicts of Interest: The authors declare no conflict of interest.

\section{References}

1. Caraveli, H. A comparative analysis on intensification and extensification in Mediterranean agriculture: Dilemmas for LFAs policy. J. Rural. Stud. 2000, 16, 231-242. [CrossRef]

2. Serrano, E.; Lavín, M.P.; Ruiz-Mantecón, A. Caracterización de Los Sistemas de Producción de Ganado Vacuno de Carne de la Montaña de León; Valle del Esla, S.A., Ed.; CSIC: León, Spain, 2002.

3. Bernués, A.; Ruiz, R.; Olaizola, A.; Villalba, D.; Casasús, I. Sustainability of pasture-based livestock farming systems in the European Mediterranean context: Synergies and trade-offs. Livest. Sci. 2011, 139, 44-57. [CrossRef]

4. Franco, J.A.; Gaspar, P.; Mesias, F.J. Economic analysis of scenarios for the sustainability of extensive livestock farming in Spain under the CAP. Ecol. Econ. 2012, 74, 120-129. [CrossRef]

5. Cocca, G.; Sturaro, E.; Gallo, L.; Ramanzin, M. Is the abandonment of traditional livestock farming systems the main driver of mountain landscape change in Alpine areas? Land Use Policy 2012, 29, 878-886. [CrossRef]

6. De Rancourt, M.; Fois, N.; Lavín, M.P.; Tchakérian, E.; Vallerand, F. Mediterranean sheep and goats production: An uncertain future. Small Rumin. Res. 2006, 62, 167-179. [CrossRef]

7. Bouju, S. Evolution des systèmes d'élevage de part et d'autre de la Méditerranée: Une difficile conciliation avec des objectifs de développement durable. Quelques réflexions à partir de deux études de cas en France (Préalpes de Digne) et en Tunisie (Khroumirie). Options Méditerr. Sér. A 2000, 39, 145-157.

8. Hadjigeorgiou, I.; Osoro, K.; De Almeida, J.F.; Molle, G. Southern European grazing lands: Production, environmental and landscape management aspects. Livest. Prod. Sci. 2005, 96, 51-59. [CrossRef]

9. Bounejmate, M.; Norton, B.E.; El Mourid, M.; Khatib, A.; Bathikha, N.; Ghassali, F.; Mahyou, H. Partnership for understanding land use/cover change and reviving overgrazed rangeland in Mediterranean areas: ICARDA's experience. Cahiers Options Méditerr. 2004, 62, 267-283.

10. Ruiz, F.A.; Mena, Y.; Castel, J.M.; Guinamard, C.; Bossis, N.; Caramelle-Holtz, E.; Contu, M.; Sitzia, M.; Fois, N. Dairy goat grazing systems in Mediterranean regions: A comparative analysis in Spain, France and Italy. Small Rumin. Res. 2009, 85, 42-49. [CrossRef]

11. Jouven, M.; Lapeyronie, P.; Moulin, C.H.; Bocquier, F. Rangeland utilization in Mediterranean farming systems. Animal 2010, 4, 1746-1757. [CrossRef] [PubMed]

12. Beaufoy, G.; Poux, X. Supporting HNV extensive livestock systems in Mountain and Mediterranean areasThe need for an adapted European Policy. Options Méditerr. 2014, 109, 19-30.

13. García-Martínez, A.; Olaizola, A.; Bernués, A. Trajectories of evolution and drivers of change in European mountain cattle farming systems. Animal 2009, 3, 152-165. [CrossRef] [PubMed]

14. Le Carignon, C.; Casabianca, F.; Torre, F.; Santucci, P.M. Primes à l'élevage bovin allaitant en Corse. Analyze des effets pervers et propositions de réorientation. Rencontre Recheches Runimants 1994, 1, 25-28. 
15. Bourbouze, A.; Gibon, A. Ressources individuelles ou ressources collectives? L'impact du statut des ressources sur la gestion des systèmes d'élevage des régions du pourtour méditerranéen. Options Méditerr. 1999, 27, 289-309.

16. Lasant, T.; Nadal-Romero, E.; Errea, P.; Arnaez, J. The Effect of Landscape Conservation Measures in Changing Landscape Patterns: A Case Study in Mediterranean Mountains. Land Degrad. Dev. 2016, 27, 373-386. [CrossRef]

17. Fernández, J.B.G.; Mora, M.R.G.; Novo, F.G. Vegetation dynamics of Mediterranean scrublands in former cultural landscape at Grazalema Mountains, South Spain. Plant Ecol. 2004, 172, 83-94. [CrossRef]

18. Bernués, A.; Riedel, J.; Asensio, M.; Blanco, M.; Sanz, A.; Revilla, R.; Casasús, I. An integrated approach to studying the role of grazing livestock systems in the conservation of rangelands in a protected natural park (Sierra de Guara, Spain). Livest. Prod. Sci. 2005, 96, 75-85. [CrossRef]

19. Saïd, S. Floristic and life form diversity in post-pasture successions on a Mediterranean island (Corsica). Plant Ecol. 2002, 162, 67-76. [CrossRef]

20. Colantoni, A.; Egidi, G.; Quaranta, G.; D’Alessandro, R.; Vinci, S.; Turco, R.; Salvati, L. Sustainable Land Management, Wildfire Risk and the Role of Grazing in Mediterranean Urban-Rural Interfaces: A Regional Approach from Greece. Land 2020, 9, 21. [CrossRef]

21. Kramer, K.; Groen, T.A.; van Wieren, S.E. The interacting effects of ungulates and fire on forest dynamics: An analysis using the model FORSPACE. For. Ecol. Manag. 2003, 181, 205-222. [CrossRef]

22. Caballero, R.; Fernandez-Gonzalez, F.; Badia, R.P.; Molle, G.; Roggero, P.P.; Bagella SPapanastasis, V.P.; Fotiadis, G.; Sidiropoulou, A. Ispikoudis IGrazing systems and biodiversity in Mediterranean areas: Spain, Italy and Greece. Pastos 2011, 39, 9-154.

23. San Miguel-Ayanz, A. Mediterranean European Silvopastoral Systems. In Silvopastoralism and Sustainable Land Management; CABI Publishing: Wallingford, UK, 2005; pp. 36-40.

24. Kormann, U.G.; Scherber, C.; Tscharntke, T.; Batary, P.; Rosch, V. Connectedness of habitat fragments boosts conservation benefits for butterflies, but only in landscapes with little cropland. Landsc. Ecol. 2019, 34, 1045-1056. [CrossRef]

25. Pecina, M.V.; Ward, R.D.; Bunce, R.G.H.; Sepp, K.; Kuusemets, V.; Luuk, O. Country-scale mapping of ecosystem services provided by semi-natural grasslands. Sci. Total Environ. 2019, 661, 212-225. [CrossRef] [PubMed]

26. Mueller, E.N.; Francke, T.; Batalla, R.J.; Bronstert, A. Modelling the effects of land-use change on runoff and sediment yield for a meso-scale catchment in the Southern Pyrenees. Catena 2009, 79, 288-296. [CrossRef]

27. Pavel, C.; d'Artis, K.; Espinosa, M. The Impact of the 2013 CAP Reform on the Decoupled Payments' Capitalisation into Land Values. J. Agric. Econ. 2018, 69, 306-337.

28. García-Martínez, A.; Bernués, A.; Olaizola, A.M. Simulation of mountain cattle farming system changes under diverse agricultural policies and off-farm labor scenarios. Livest. Sci. 2011, 137, 73-86. [CrossRef]

29. Lorent, H.; Sonnenschein, R.; Tsiourlis, G.; Hostert, P.; Lambin, E. Livestock subsidies and rangeland degradation in central Crete. Ecol. Soc. 2009, 14. [CrossRef]

30. Lefebvre, M.; Espinosa, M.; Gomez y Paloma, S. The influence of the Common Agricultural Policy on agricultural landscapes. Eur. Comm. Jt. Res. Cent. 2012, 7. [CrossRef]

31. Andersen, E.; Rutherford, A.; Winter, M. The CAP Regimes and the European Countryside: Prospects for Integration between Agricultural, Regional and Environmental Policies; Lowe, P., Brouwer, F.M., Eds.; CABI Pub: New York, NY, USA, 2000; pp. 55-70.

32. Santucci, P.; Fabre, J.; Paoli, J.-C. Rôle des Parcours en Élevage Pastoral Corse; INRA: Paris, France, 2011; 37p.

33. Bartolomé, J.; Franch, J.; Plaixats, J.; Seligman, N.G. Grazing alone is notenough to maintain landscape diversity in the Montseny Biosphere Reserve. Agr. Ecosyst. Environ. 2000, 77, 267-273. [CrossRef]

34. Simi, P. Precis de Géographie de la Corse, Societé des Sciences Historiques et Naturelles de la Corse; Perriquet Editeur: Corte, France, 1981.

35. Cristofini, B.; Deffontaines, J.-P.; Raichon, C.; De Verneuil, B. Pratiques d'élevage en Castagniccia. Exploration d'un milieu naturel et social en Corse. Études Rural. 1978, 71-72, 89-109. [CrossRef]

36. Vercherand, J. La question du développement de l'élevage en Corse. Etudes Corses 1989, 32, 5-77. [CrossRef]

37. Lafitte, L.M. Analyse-Diagnostic de L'agriculture de la Castagniccia (Corse); Master's Dissertation, Agroparistech: Paris, France, 2012. 
38. Alados, C.L.; ElAich, A.; Papanastasis, V.P.; Ozbek, H.; Navarro, T.; Freitas HVrahnakis, M.; Larrosi, D.; Cabezudo, B. Change in plant spatial patterns and diversity along the successional gradient of Mediterranean grazing ecosystems. Ecol. Model. 2004, 180, 523-535. [CrossRef]

39. Biondini, M.; Kandus, P. Transition matrix analysis of land-cover change in the accretion area of the Lower Delta of the Paraná River (Argentina) reveals two succession pathways. Wetlands 2006, 26, 981-991. [CrossRef]

40. Hu, Y.; Zhen, L.; Zhuang, D. Assessment of land-use and land-cover change in Guangxi, China. Sci. Rep. 2019, 9, 1-13. [CrossRef]

41. Osoro, K.; Ferreira, L.M.M.; Garcia, U.; Martinez, A.; Celaya, R. Forage intake, digestibility and performance of cattle, horses, sheep and goats grazing together on an improved heathland. Anim. Prod. Sci. 2017, 57, 102-109. [CrossRef]

42. Doi, K.; Tamiya, S.; Nakajima, N.; Yayota, M. Sustainable goat grazing for managing abandoned fields: Dynamics of vegetation quality, quantity and nutritional status of goats over five years. Grassl. Sci. 2020, 66, 16-28. [CrossRef]

43. Alvarez-Martinez, J.; Gomez-Villar, A.; Lasanta, T. The Use of Goats Grazing to Restore Pastures Invaded by Shrubs and Avoid Desertification: A Preliminary Case Study in the Spanish Cantabrian Mountains. Land Degrad. Dev. 2020, 27, 3-13. [CrossRef]

44. Garcia, R.R.; Fraser, M.; Celaya, R.; Mendes Ferreira, L.M.; Garcia, U.; Osoro, K. Grazing land management and biodiversity in the Atlantic European heathlands: A review. Agrofor. Syst. 2013, 87, 19-43. [CrossRef]

45. Osoro, K.; Martínez, A.; Celaya, R. Effect of breed and sward height on sheep performance and production per hectare during the spring and autumn in Northern Spain. Grass Forage Sci. 2002, 57, 137-146. [CrossRef]

46. Kizos, T.; Plieninger, T.; Schaich, H. Instead of 40 Sheep there are 400: Traditional Grazing Practices and Landscape Change in Western Lesvos, Greece. Landsc. Res. 2013, 38, 476-498. [CrossRef]

47. Psyllos, G.; Kizos, T.; Hadjigeorgiou, I.; Dimitrakopoulos, P.G. Grazing Land Management and Sheep Farm Viability in Semi-Arid Areas: Evidence from Western Lesvos, Greece. Options Méditerranéennes. Series A: Mediterranean Seminars. 2016. Available online: http://agris.fao.org/agris-search/search.do?recordID= QC2018600130 (accessed on 27 February 2018).

48. Chatellier, V.; Guyomard, H.; Bris, K.L. La diversité des exploitations professionnelles du type bovins-viande dans l'Union européenne. Économie rurale. Agric. Aliment. Territ. 2005, 288, 9-23.

49. Gutman, M.; Henkin, Z.; Holzer, Z.; Noy-Meir, I.; Seligman, N.G. A case study of beef-cattle grazing in a Mediterranean-type woodland. Agrofor. Syst. 2000, 48, 119-140. [CrossRef]

50. Calleja, J.A.; Escola, M.; Carvalho, J.; Forcadel, J.M.; Serrano, E.; Bartolome, J. Cattle Grazing Fails to Control Shrub Encroachment in Mediterranean Landscapes. Rangel. Ecol. Manag. 2019, 72, 803-811. [CrossRef]

51. Jones, N.; Duarte, F.; Rodrigo, I.; van Doorn, A.; de Graaff, J. The role of EU agri-environmental measures preserving extensive grazing in two less-favoured areas in Portugal. Land Use Policy 2016, 54, 177-187. [CrossRef]

52. Galanopoulos, K.; Zaphiris, A.; Vassiliki, L.; Hatziminaoglou, I.; Boyazoglu, J. The Technical Efficiency of Transhumance Sheep and Goat Farms and the Effect of EU Subsidies: Do Small Farms Benefit More than Large Farms? Small Rumin. Res. 2011, 100, 1-7. [CrossRef]

53. Garcia-Launay, F.; Sibra, C.; Molenat, H.; Agabriel, C.; Brunschwig, G. Grassland use in mountain bovine systems according to a hierarchy of geographical determinants. J. Agric. Sci. 2012, 150, 203-217. [CrossRef]

54. Holmstrom, K.; Hessle, A.; Andersson, H.; Kumm, K.I. Merging Small Scattered Pastures into Large Pasture-Forest Mosaics Can Improve Profitability in Swedish Suckler-Based Beef Production. Land 2018, 7, 58. [CrossRef]

55. Gourdouvelis, D.; Dotas, V.; Kaimakamis, I.; Zagorakis, K.; Yiakoulaki, M. Typology and structural characterisation of suckler cow farming system in Central Macedonia, Greece. Ital. J. Anim. Sci. 2019, 18, 1082-1092. [CrossRef]

56. Peer, G.; Bonn, A.; Bruelheide, H.; Dieker, P.; Eisenhauer, N.; Feindt, P.H.; Hagedorn, G.; Hansjürgens, B.; Herzon, I.; Lomba, Â.; et al. Action needed for the EU Common Agricultural Policy to address sustainability challenges. People Nat. 2020, 2, 305-316. [CrossRef]

57. European Commission, Future of the Common Agricultural Policy. Available online: https://ec.europa.eu/info/ food-farming-fisheries/key-policies/common-agricultural-policy/future-cap_en (accessed on 31 March 2020).

58. Europe Direct, Programmes Européens 2021-2027: PAC Après 2020. 2018. Available online: https: //www.europedirectpyrenees.eu/agriculture/2021-2027-pac (accessed on 2 June 2018). 
59. CAPeye. Propositions et Réactions Pour la Future PAC. Available online: https://www.supagro.fr/capeye/ propositions-et-reactions-pour-la-future-pac// (accessed on 11 June 2018).

Publisher's Note: MDPI stays neutral with regard to jurisdictional claims in published maps and institutional affiliations.

(C) 2020 by the authors. Licensee MDPI, Basel, Switzerland. This article is an open access article distributed under the terms and conditions of the Creative Commons Attribution (CC BY) license (http://creativecommons.org/licenses/by/4.0/). 